Wertheim 37, p. 74-76.

10. Relativamente a esse "judaísmo originariamente aristocrático", torna-se manifesto ao mesmo tempo, também, em Langbehn, até que nível despencara o novo judaísmo que vivia na Alemanha e arrastara consigo a cultura alemã.

11. Somente em 1944 aparece com Fritzsche em Berlim uma nova Edição, preparada por Gerhard Krüger, na qual todas as referências positivas a Espinosa são removidas. 12. 1937: Prêmio Goethe da cidade de Frankfurt am Main; 1938: Escudo da Águia do Império Alemão; 1941: Plaqueta-Kant da cidade de Königsberg; 1944: PrêmioGrillparzer.

13. Ofício da Câmara Oficial do Reich para esclarecimento popular e propaganda, dirigido à Livraria Universitária Carl Winters, de 27.1.44.

A passagem incriminada começa da seguinte maneira: "Jamais ao longo da Idade Média o judaísmo desenvolvera um ramo tão imponente do povo decaído e espalhado pelo mundo, um florescimento tão elevado da cultura e da prosperidade, da ciência e do trabalho artístico, quanto na Espanha". (Fischer 8, p.2.)

14. A sua contribuição para o debate está publicada no $1^{\circ}$ dos, ao todo, 9 cadernos da Série abrangente sobre "Das Judentum in der Rechtswissenschaft" ("O judaísmo na ciência do direito"), que traz o título: Die deutsche Rechtswissenschaft im Kampf gegen den jüdischen Geist. (A ciência do direito alemão em luta contra o espírito judeu). O caderno também contempla a abertura e a conferência de encerramento de Carl Schmitt.

15. Isso não foi algo que "judeus alegaram”, mas o próprio Goethe o falou acerca do efeito da sua leitura da Ética de Spinoza!

16. Isso soa fortemente a uma retomada, p. ex., da crítica que Eduard von Hartmann formulou contra Espinosa (veja acima, na seção 2.1).

17. Sobre a diferença fundamental entre Espinosa e Nietzsche, veja lá na p. 95 , anotação 2, sobre o caráter judaico da doutrina da multidão de Cantor e a física de Einstein, p.103, anotação 1, e p.107.

18. Primeiro em München 1920; depois seguem mais quatro edições, dentre as quais, três na Editora Central da NSDAP e, por fim, na 34.-53. Tsd. München 1943.

19. Somente a Spinozas Ethic. Eine kritische Einführung (A Ética de Espinosa. Uma introdução crítica) de Hans M. Wolff aparece já em 1958, em Francke in Bern. Wolff, jurista promovido com fortes inclinações para literatura e filosofia; após o seu segundo doutorado em Germanística, leciona na Brown University, em Providence, na Ilha de Rhode, e não retorna mais para a Alemanha. Ele morre em 1958. Ver Karl S. Guthke, Hans M. Wolff - em vez do Monatshefte necrológico 51,4 (1959): 193-196.

\section{EXPERIMENTAÇÃO POLÍTICA DA AMIZADE A PARTIR DA TEORIA DOS AFETOS DE ESPINOSA}

Lívia Godinho Nery Gomes*

Nelson da Silva Júnior*

Resumo: A amizade é concebida neste estudo como tendo um sentido político, pois uma condição necessária do exercício político é aquela de considerar a opinião do outro. Em seu sentido político, a amizade favorece o questionamento de pontos de vista fixos e a irrupção de ações inovadoras. A experimentação política da amizade constitui uma relação agonística, de abertura ao outro na qual os corpos estão dispostos a afetar e serem afetados, implicados em contribuir com o aumento da capacidade de reflexão e ação do amigo. Este artigo tem como objetivo discutir a experimentação política da amizade a partir da teoria dos afetos de Baruch Espinosa: o corpo é essencialmente relacional e é na relação com seus outros, na maneira como afeta e é afetado por eles que se dá a condição de possibilidade da resistência à tristeza e afirmação da alegria compreendida como aumento da potência de pensar e agir.

Palavras-chave: amizade, experimentação, política, afetos, Espinosa

A amizade compreendida em sua qualidade política, ou seja, enquanto vínculo agonístico que permite transformações no registro da subjetividade, diz respeito à potência dos encontros e às forças mobilizadas por estes. Neste sentido, a questão da experimentação política da amizade

* Professora Adjunta do departamento de Psicologia da Universidade Federal de Sergipe. O presente artigo refere-se a uma parte da tese de doutorado, intitulada "Implicações políticas das relações de amizades mediadas pela internet”. A pesquisa foi realizada com apoio financeiro da Fundação de Amparo à Pesquisa do Estado de São Paulo (FAPESP).

** Professor Livre Docente do Departamento de Psicologia Social e do Trabalho do Instituto de Psicologia da Universidade de São Paulo. 
pode ser remetida à noção espinosana de força dos afetos, em sua Ética. Pensar amizade à luz da filosofia espinosana dos afetos, mais do que um caminho apropriado, parece-me uma oportuna escolha elucidativa. A experimentação política da amizade condensa em si um dos principais postulados da filosofia de Espinosa: “o corpo humano pode ser afetado de muitas maneiras, pelas quais sua potência de agir é aumentada ou diminuída, enquanto outras não tornam sua potência de agir nem maior nem menor" (E.III. postulado 1. p. 163). Pois a compreensão da amizade em sua qualidade política designa um vínculo privilegiado de abertura à alteridade, que permite ao corpo experimentações de afetar outros corpos e por eles ser afetado, cujos efeitos podem suscitar transformações no registro da subjetividade, ou ainda da potência de agir. $\mathrm{O}$ presente artigo, que corresponde a uma parte de uma tese de doutorado em Psicologia Social sobre as Implicações políticas das relações de amizades mediadas pela internet, tem como objetivo discutir a experimentação política da amizade à luz da teoria dos afetos em Espinosa.

\section{É Preciso estar atento e forte}

A Ética espinosana é a exaltação da ética da alegria que nos conduz à ideia adequada de nós mesmos e de Deus. Ela concerne a uma maneira de ser que nos convoca a buscar união com as coisas e seres que fortalecem nosso corpo e alma, ao invés de permanecermos ao acaso dos encontros. A Ética envolve uma experimentação implicada com a elucidação de questionamentos de ordem prática: se a consciência é também o território das ilusões e é natural ter ideias confusas, incertas, como se tornar consciente de si mesmo e de Deus? Como passar das paixões tristes às paixões alegres a partir das quais passamos aos afetos ativos? Como se tornar causa adequada, ou seja, como chegar a ser causa total dos efeitos de nossos afetos?
Segundo Espinosa, a possibilidade da ética encontra-se na conservação do conatus como fundamento único da virtude. "A virtude é a própria potência humana, que é definida exclusivamente pela essência do homem, isto é, que é definida pelo esforço pelo qual o homem se esforça por perseverar em seu ser" (E. IV, demonstração da preposição 20, p. 289). Logo, a chave da ética está no esforço para fortalecer o conatus, o que supõe uma abertura para afetar de múltiplas maneiras outros corpos e por eles ser afetado, compondo relações que visem a contribuir ao aperfeiçoamento da potência de agir dos outros corpos e também por eles ser revitalizado. Em outras palavras, a virtude supõe uma disposição afetiva, um gosto para relacionar-se com a capacidade para pensar e interpretar seus próprios apetites e desejos nesses relacionamentos, passando das ideias inadequadas às adequadas. É no âmbito de nossas relações afetivas que há a possibilidade de nos descobrirmos como causas adequadas de nossos apetites e ideias. Ou seja, é através de nossos próprios afetos que podemos nos tornar causa adequada de nossos apetites e desejos, fortalecendo nosso conatus.

Desse modo, não estamos confinados aos maus encontros e às tristezas. A vida ética implica a passagem das paixões tristes às alegres, portanto da fraqueza à força, que nos afasta da passividade e nos abre para a ação. A ética é, assim, uma possibilidade que nasce dos próprios afetos e implica o esforço para estarmos atentos ao nosso corpo e em sintonia com os nossos desejos. É um convite a entrarmos em contato com as singularidades de nosso corpo, conhecendo-o em suas necessidades e limitações, assumindo o risco das descobertas de suas novas potências e fragilidades nas suas afecções. A vida ética começa se estivermos plenos de coragem e livres para lançarmo-nos na aventura de descobrir o que pode o nosso corpo em relação, para que então possamos orientar nossas ações com base em nossos afetos alegres. Portanto, a Ética espinosana implica uma prática, uma experimentação de maneiras de nos deixarmos contagiar 
pela alteridade, para conhecer o que fortalece nosso conatus, de modo que estejamos aptos a constituir encontros alegres. Segundo Bove, na prática de composição de relações, a lógica amorosa dá certamente ao sujeito ético a matriz teleológica de sua ação (segundo o princípio da busca do útil próprio); no entanto, é na razão que o sujeito encontra a sua determinação ética fundamental: quando se livra das ilusões próprias ao sujeito amoroso, pelo conhecimento adequado das causas de sua ação, ou seja, de seus próprios afetos, abre-se caminho para a virtude decorrente do fato de que se vive sob a condução da razão. $O$ conhecimento adequado de nossos afetos é já um acontecimento ético, uma potência em ato de humanidade e de amor - própria do afeto ativo. A ação virtuosa é, então, afirmação da unidade ética do sujeito, afirmação de sua potência e autonomia.

O caminho ético pressupõe o cuidado com o corpo, possibilitando que ele seja afetado ao máximo por afetos de alegria. Espinosa nos diz que quanto mais somos afetados por alegria, mais passamos à perfeição e participamos da natureza divina; portanto, o homem virtuoso e sábio procura recompor o corpo com refeições saudáveis e usufrui do atrativo das plantas verdejantes, das artes, do esporte, da música, do teatro como alimentos que revigoram o corpo e a alma. O cuidado de si, como nos lembra Foucault (2004), é ético em si mesmo e constitui uma prática da liberdade que implica também uma maneira de cuidar dos outros. A ética encontra-se na possibilidade de fortalecimento do conatus, tornandonos causa adequada de nossos desejos para que possamos passar da passividade a uma afetividade ativa que busca transmitir aos outros afetos de alegria. O comprometimento ético envolve o esforço em contribuir com o engrandecimento da potência de agir dos outros, contagiando-os com afetos de alegria, como o amor, gentileza, amizade, generosidade etc. Bove fala da benevolência como afeto que se constitui na raiz da busca do princípio do prazer (ou do útil próprio) e da resistência à tristeza que este envolve. A beatitude (glória), que é a virtude em si mesma, se constitui na afirmação da potência de composição e de organização dos corpos no processo de resistência que cada ser opõe ao que pode tirar sua existência. A benevolência pela qual nos esforçamos para libertar o outro de sua miséria nasce da experiência compartilhada de afirmação da vida, numa verdadeira dinâmica de resistência à tristeza, na qual a ajuda ao semelhante recompõe não só a vida no outro, mas em nós mesmos. É nesse sentido que Bove afirma que a aversão da vida à tristeza exprime já a verdade de toda ética.

O sujeito é então ao mesmo tempo potência de afirmação e de resistência. Tornar-se sujeito ${ }^{1}$, nos lembra Bove, não é o destino natural da natureza humana, trata-se de um processo, uma empreitada, é o projeto humano por excelência, sua possibilidade ética. $\mathrm{Na}$ ética da resistência e do amor é a existência singular ela mesma em sua afirmação absoluta que é tornada sujeito; nesse sentido, Bove afirma que "o sujeito ético é então uma intenção sem fim, uma perfeição sem modelo, isto é, a tensão mesma da existência singular em sua afirmação absoluta e produtiva" (Bove 3, p. 143). O projeto ético implica encontrar a relação de confiança e de amor que ao mesmo tempo envolve e desenvolve toda vida em sua essencial afirmação.

A passagem aos afetos ativos em nossos relacionamentos requer a disposição para atingirmos as pessoas com afetos de alegria, comprometidos com a expansão do amor em nossas relações cotidianas, atuando como força que pode transformar inclusive o ódio. Segundo Espinosa, quanto mais somos livres e vivemos sob a condução da razão, tanto mais implicados estaremos em retribuir os afetos de ódio, como a ira e o desprezo de alguém, com amor e generosidade, de tal maneira que convertamos o ódio em amor.

A grandiosa inovação de Espinosa em sua Ética foi demonstrar a força dos afetos. "O ódio é aumentado pelo ódio recíproco, e contrariamente, 
pode ser eliminado pelo amor" (E.IV, demonstração da proposição 46. p.321). Logo, o comprometimento ético supõe o esforço para cultivar o amor em nossas relações afetivas, buscando sempre contribuir com o crescimento da potência de existir dos outros. O empenho dos sentimentos ativos em não ser afligido por afetos de ódio implica também o esforço para que outras pessoas não padeçam desses afetos.

A conduta ética supõe o exercício ativo e criativo de nossos investimentos afetivos. A gravidade de tal tarefa torna-se ainda mais relevante no atual contexto de subordinação da subjetividade e dos afetos ao registro econômico. Na contemporânea conjuntura de apropriação da afetividade pelos imperativos do mercado é preciso estar atento e não se deixar levar pelas estratégias sedutoras do mercado que visam a todo instante capturar o consumidor através da manipulação de seus afetos com falsas promessas de felicidade que não condizem propriamente com o fortalecimento de seu conatus.

\section{Amizade e alegria da Hilaritas: caminho de produção das ideias adequadas}

A alegria da Hilaritas $^{2}$ é positivamente constitutiva, já que ela relaciona-se com o aumento da potência de agir e, sobretudo com o movimento mesmo de afirmação do ser. Bove destaca a Hilaritas como a expressão adequada do pressuposto por excelência da existência ética. As relações de amizade, na medida em que constituem uma abertura a ser afetado e a afetar, possibilitam este afeto particular de alegria, pois de acordo com Bove a ocasião da constituição dessa alegria, originária da razão, se dá a partir das circunstâncias felizes quando o corpo apresenta várias aptidões de afetar e ser afetado. É nesse sentido que Espinosa afirma que "a força do desejo que surge da alegria deve ser definida pela potência humana e, ao mesmo tempo, pela potência da causa exterior" (E. IV. demonstração da proposição 18, p. 287). Portanto, os laços de amizade favorecem uma dinâmica da alegria onde forças se adicionam abrindo caminho para a produção de ideias adequadas - condição de nossa liberdade e da passagem dos afetos passivos aos afetos ativos. Bove, ao falar da dinâmica da ascensão da razão pela alegria, afirma que a alegria da Hilaritas, sempre boa e sem excesso, é o afeto passivo que permite a expressão da razão. Segundo o autor, a Hilaritas indica um processo no qual nenhum afeto é contrário à nossa natureza e por isso mesmo não impede o pensamento; portanto ela não é essencialmente passiva, pois é uma via ativa do conhecimento primeiramente das noções comuns, e das ideias adequadas. Bove refere-se à alegria da Hilaritas praticamente como uma potência favorável ao conhecimento de noções comuns na medida em que por este afeto o corpo tem já uma riqueza de aptidões de afetar e ser afetado, sendo suas partes igualmente afetadas por causas exteriores - o que significa que ele é afetado por qualquer coisa que é comum em todas suas partes e/ou qualquer coisa que é também comum com o outro corpo considerado. Portanto, a passividade extrínseca da Hilaritas é imediatamente correlativa de uma real atividade que é a da razão. De acordo com Bove as afecções que permitem aos homens entrar em acordo devem ser consideradas em sua atividade, pois exprimem propriedades comuns relativas à essência mesma dos corpos considerados. Sobre essa dinâmica do advento da razão, como processo mesmo de conhecimento das noções comuns e ideias adequadas pela alegria Espinosa afirma: "Será adequada na mente a ideia daquilo que o corpo humano e certos corpos exteriores pelos quais o corpo humano costuma ser afetado têm de comum e próprio, e que existe em cada parte assim como no todo de cada um desses corpos exteriores" (E. II. proposição 39, p.129). Conforme afirma Chaui "somos ativos ou agimos quando somos causas eficientes totais dos efeitos que se 
produzem em nós e fora de nós" (Chaui 8, p. 86), já na passividade "somos causa inadequada de nossos apetites e de nossos desejos, isto é, somos apenas parcialmente causa do que sentimos, fazemos e desejamos, pois a causa mais forte e poderosa é a imagem das coisas, dos outros e de nós mesmos, portanto, a exterioridade causal é mais forte e mais poderosa do que a interioridade causal corporal e psíquica" (Chaui 8, p. 88). Ou seja, na paixão, a força externa é mais poderosa do que a do conatus, enquanto na ação há uma conjugação de forças de seres que possuem propriedades, qualidade e características comuns.

A condição mesma da formação da noção comum está no encontro de nosso corpo com outros corpos e das forças que aí estão em jogo, geradoras de flutuações de nossa potência de agir que são acompanhadas de um afeto de alegria ou tristeza que nosso corpo se esforça para manter ou reduzir. $\mathrm{Ou}$ seja, é no âmbito de nossas relações cotidianas, compreendidas como relações de forças, numa resistência-ativa à tristeza que o conatus tende a se estender como razão, segundo forças exercidas nele (e por ele) e que lhe permitem pensar verdadeiramente. É nesse sentido que na vida prática a amizade é uma relação afetiva que possui um papel essencial nas modificações do espírito bem como na base da produção das ideias verdadeiras, constituindose, conforme diz Bove, como remédio contra os afetos passivos.

\section{Amizade e fortalecimento do conatus: resistência à tristeza pela benevolência e indignação ou amizade: recusa do servir}

$\mathrm{Na}$ relação de amizade, os amigos revigoram o ânimo pela simples companhia e prazer de estarem juntos. A amizade é em si mesma a expressão da condição da liberdade e fortalecimento do conatus. Pois, segundo Espinosa, o homem livre e forte não tem raiva nem inveja de ninguém, não é arrogante e busca combater o ódio. A amizade concerne à condição vital do homem de poder afetar e ser afetado, de maneira tão íntegra, que Espinosa considera lealdade o desejo do homem de unirse aos outros pela amizade, e desleal aquilo que contraria o vínculo de amizade (E. IV. escólio 1 da preposição 37). Se a amizade constitui-se como uma possibilidade da passagem dos afetos passivos aos ativos, ela favorece o processo ético bem como o conhecimento das noções comuns e ideias adequadas constitutivo dessa empreitada. A condição do viver com (conviver), onde os amigos compartilham ideias e valores, propicia a formação das noções comuns, como conhecimento do modo de relação entre seres singulares. Em outras palavras, as trocas de opiniões, de ideias, valores etc. no diálogo entre amigos possibilitam o conhecimento das noções comuns, isto é, das propriedades comuns que lhes permitem se reconhecerem como homens (modos finitos, no vocabulário espinosano).

Espinosa refere-se à amizade como um afeto de alegria, útil aos homens livres, pois os conduz a fazer bem uns aos outros e os capacitam para ação comum. "É útil aos homens, acima de tudo, formarem associações e se ligarem por vínculos mais capazes de fazer de todos um só e, mais geralmente, é-lhes útil fazer tudo aquilo que contribui para consolidar as amizades" (E. IV, Apêndice, capítulo 12. p.353). Portanto, a amizade é útil, pois aumenta a capacidade de agir dos homens.

Portanto, a amizade é em si mesma uma condição de abertura aos encontros alegres. Segundo Hardt (1996), a política de Espinosa é uma política ontológica, pois os princípios que mobilizam a organização política são os mesmos que animam a ética e a prática afirmativa do ser. Este autor afirma que o encontro alegre se dá quando dois corpos compõem um corpo novo e mais poderoso, ou seja, quando a afecção com outro corpo torna-se ativa a partir da construção da noção comum, isto é, quando formamos a ideia da relação comum partilhada por esse corpo e o nosso. O aspecto ontológico da política espinosana é elucidado por Chaui (2003) 
que chama atenção para o fato de que é a teoria mesma das paixões e dos desejos alegres, ou seja, dos afetos que fortalecem o conatus que oferecem os fundamentos da utilidade da cooperação e da união de forças entre os homens para a composição do corpo político - a multitudo, de "tal maneira que a percepção dos demais homens como semelhantes e da utilidade de cada um deles e de todos para o fortalecimento do conatus individual explica que constituam a multitudo e instituam o corpo político"(Chaui 6, p. 165). É nesse sentido que se funda a relevância política da amizade para o fortalecimento da multitudo, pois a amizade possibilita uma dinâmica da alegria favorável ao florescimento da solidariedade e da mobilização para que os homens ajam juntos numa condição de igualdade política onde não há dominação - o que designa a amizade em sua qualidade democrática. Chaui (2003) ressalta que a democracia é para Espinosa o "mais natural dos regimes políticos" precisamente porque "nela se realiza o desejo natural de todos e de cada um, qual seja, governar e não ser governado"(Chaui 6, p. 171). Com efeito, a amizade é essencialmente democrática não só porque constitui uma condição de igualdade política, mas também porque designa uma relação agonística de abertura ao outro que favorece a livre circulação e expressão das mais diferentes opiniões. Bove destaca a liberdade de expressão das opiniões diversas, das paixões e dos interesses divergentes como constitutiva dos Estados democráticos, afirmando que para Espinosa os conflitos não representam somente o sinal da liberdade no Estado, mas também aquele da perpetuação, da promoção e da defesa desta liberdade mesma.

A afetividade ativa da ética espinosana concerne à experimentação política da amizade destacada por Arendt (2001), Derrida (1997), Ortega (2000), pois esta experiência constitui um vínculo agonístico entre alteridades que se afetam mutuamente aumentando suas potências de agir, podendo juntos produzir ações políticas inovadoras. Em pesquisa anterior sobre a experimentação política da amizade (Gomes e Silva Junior 13) pudemos verificar que de fato as relações de amizade possibilitam trocas de experiências e aprendizagens que produzem transformações subjetivas que aumentam a potência de agir e fortalecem o conatus. Com efeito, os sujeitos mostraram-se comprometidos em contribuir para o crescimento dos amigos, determinados em aumentar sua força para existir, como no caso em que o gosto por esporte é potencializado por um amigo que ensina o outro a nadar, ou quando amigos se organizam coletivamente para vencer o desemprego formando uma cooperativa (Gomes e Silva Junior 13). Os obstáculos e privações produzidos pela dominação econômica são, muitas vezes, contornados pelas relações de amizade, em que o amigo, numa atitude ética e política, reconhece o outro como cidadão. As narrativas desvelaram laços de amizade como relações de fortalecimento do conatus, como encontros alegres nos quais os amigos modificam-se, potencializam habilidades, aguçam desejos ainda não realizados, instigam a esperança de sonhos ainda não alcançados. Através de seus laços de amizade, os sujeitos das classes populares demonstram formas de organização e de luta, mobilizadas pela força da solidariedade, resistindo a condições opressivas e compondo a amizade como uma recusa do servir - como discute Chaui (1999).

A resistência, conforme afirma Bove, implica razão e virtude. Segundo ele, a virtude do corpo coletivo é a sua potência de composição e de organização que Espinosa identifica como afirmação absoluta da potência da multidão. A estratégia de resistência-ativa do conatus do corpo coletivo (multidão) nasce do gesto de querer bem a outro - próprio da amizade, na busca em combater o mal que lhe acomete e de livrá-lo de sua miséria. Esse desejo de fazer o bem e de destruir a causa da tristeza do outro - caro entre amigos, constitui a virtude da potência da multidão de onde brota o seu movimento de organização e resistência. É nesse sentido que 
Bove fala do pensamento político de Espinosa como um combate no qual a benevolência e a indignação são os afetos por excelência da resistência da multidão. Não admitir o sofrimento de um amigo, não suportar a sua tristeza é já o movimento de resistência que opera a benevolência. Embora a indignação seja um afeto passivo, já que é um afeto de ódio, definida por Espinosa (2008) como "ódio por alguém que fez mal a um outro" (E.III, definição dos afetos, 20, p.245). Bove aponta um aspecto positivo na raiz deste ódio: a relação de identificação entre os semelhantes, até mesmo de amor, que nos conduz a agir para livrar de sua miséria aqueles que foram acometidos por um mal ${ }^{3}$. Nesta dinâmica de resistência à tristeza, a benevolência na indignação se volta contra os afetos que decompõem a vida e, em meio à condição de servidão, constitui-se como origem de liberdade e de virtude pela qual se afirma a potência auto-organizadora da multidão. Portanto, "a resistência da multidão se explica pela potência da afirmação da vida e não pela impotência que os sentimentos de piedade e de ódio exprimem" (Bove 3, p. 294, tradução minha). Indignar-se como ação oriunda da solidariedade e generosidade - gestos que a amizade emana, é já resistência como fruto do amor e da esperança bem como do esforço pela constituição da humanidade do homem.

Como reconstituição do tecido social na e pela solidariedade que ela envolve e a dinâmica libertadora que suscita, a indignação é, então, um remédio que o corpo coletivo produz e aplica a si mesmo. Ela é o processo mesmo de uma autodefesa e de uma autocura. É então da Alegria que acompanha a cólera da indignação - uma alegria (que é "satisfação de si") pela qual o corpo coletivo experimenta e contempla através daqueles que solidariamente resistem, o aumento de sua própria potencia de agir, o renascimento de sua 'saúde'. Uma alegria inseparável do amor natural de si, este afeto fundamental de onde nasce toda resistência, e com ela a esperança em ato, na indignação geral, do acontecimento da multidão como sujeito autônomo. Na resistência à dominação se elabora assim a dinâmica da subjetividade coletiva (política) como processo. Dinâmica da alegria que vai se amplificando na e pela instituição política da Liberdade que é a plenitude deste amor natural de si do corpo coletivo que envolvia já, na indignação, o ato de resistência (Bove 3, p. 294-295, tradução minha).

É essencialmente em atos, no registro da prática das relações cotidianas e pelos valores que as perpassam que a resistência se expressa como afirmação da vida, da solidariedade, da liberdade. A benevolência e a indignação, destacadas por Bove como afetos da resistência, de fato só emergem do comprometimento com o outro, da gravidade do existir para o outro que me interpela e exige de mim uma resposta - que é já a responsabilidade por ele, tal como compreende Lévinas (2005). Segundo Lévinas, o encontro com outrem é já minha responsabilidade por ele. $\mathrm{O}$ 'eu' questiona-se e se transforma neste encontro em que é afetado e investido pela alteridade irredutível do outro, responsável por este numa condição de não indiferença diante de sua morte e sofrimento. A benevolência e a indignação brotam de relações intersubjetivas imbuídas do gosto pelo outro - concernente à amizade, nas quais a livre circulação da palavra permite a afirmação de multiplicidades, contra o assujeitamento, no processo mesmo de ação coletiva. Bove (1996) afirma que a estratégia de liberação política em Espinosa se apóia na resistência das relações implicadas com a produção de subjetividades que afirmam em ato, contra a inumanidade e a indignidade do assujeitamento (produtor de rebanhos de escravos), uma singularidade humana que envolve a esperança política da liberdade:

Pois essas singularidades que resistem instauram já no presente, em diametral oposição ao reino da servidão, que é 
também aquele da solidão, do ódio, da mentira e da perfídia ('corrupção de todas as relações sociais'), a benevolência e o amor, a franqueza, a liberdade da comunicação e da palavra, com o desejo de conhecer, de agir e viver juntamente (Bove 3, p. 299-300, tradução minha).

\section{Experimentação política da amizade e multidão (multitudo): aumento da potência de agir}

A potência da qualidade política da amizade está na possibilidade de experimentação de abertura à alteridade numa condição de não impedimento da palavra, onde os sujeitos através das trocas de opiniões e ideias podem questionar pontos de vista fixos e alcançar um nível de reflexão crítica que é em si mesma mobilizadora de movimentos de resistência e de transformação de subjetividades. Pensar a amizade como espaço de experimentação capaz de irromper formas fixas de subjetividade e sociabilidade, constituindo uma forma de resistência política, representa um convite a uma forma de contato desafiadora e inquietante, na qual é possível vivenciar o sentimento de certo mal estar, de "perda de referencial", trazidos pela experiência de revelação e alargamento de opiniões no encontro com outros. A amizade compreendida em sua qualidade política constitui uma disposição em afetar e ser afetado num contexto de conversas horizontais onde os sujeitos se desestabilizam e podem ver o mundo a partir de outra perspectiva.

O elemento político, na amizade, reside no fato de que, no verdadeiro diálogo, cada um dos amigos pode compreender a verdade inerente à opinião do outro. Mais do que o seu amigo como pessoa, um amigo compreende como e em que articulação específica o mundo comum aparece para o outro que, como pessoa, será sempre desigual ou diferente. Esse tipo de compreensão - em que se vê o mundo (como se diz hoje um tanto trivialmente) do ponto de vista do outro - é o tipo de insight político por excelência (Arendt 1, p. 99).

A amizade na concepção arendtiana do termo é respeito e interesse pela opinião dos outros, não depende de intimidade, consiste no gosto pela opinião do outro, configurando uma relação desconcertante, "agonística", na qualé possível vivero deslocamento/questionamento do familiar, deslocandose para o lugar dos outros. A amizade compreendida em sua qualidade política é antes uma relação de abertura à expressão de opiniões as mais diversas - 0 que favorece um campo propício para a formação de ideias adequadas e da reflexão crítica. É nesse sentido que devemos conferir dignidade à amizade como filosofia em ato. Ora, cabe à filosofia defender e mesmo produzir este campo aberto à diversidade de ideias, sem o qual ela não seria possível. Conforme atenta Bove, a estratégia da multidão implica a conquista do espaço público da livre expressão das opiniões; na medida em que "um pensamento é limitado por um outro pensamento" " 4 problema político é um problema de espaço a ser produzido e defendido. Em outras palavras, Bove afirma que a estratégia por excelência do conatus político, ou da multitudinis potentia, concebida como movimento ao mesmo tempo livre e necessário de auto-constituição da sociedade como corpo, se origina no exercício plural da liberdade da palavra de seus sujeitos. Portanto, a experimentação política da amizade como relação de abertura à livre expressão de opiniões configura um terreno fértil onde podem germinar ações de organização da multidão, viabilizando sua potência. A força da qualidade política da amizade, destacada por Arendt (1993) e Derrida (1997), encontra-se na possibilidade de resistência à redução da expressão de opiniões - própria do estreitamento e cegueira da superstição (condição de ausência de reflexão crítica favorável à servidão) a partir de uma relação agonística de afrontamento de diferentes e múltiplas opiniões, interesses, potências singulares de análise, de crítica, de 
indignação que pode irromper ações políticas inovadoras. A amizade como vínculo privilegiado de consideração da opinião do outro promove encontros de trocas de experiências, valores e idéias que produzem transformações no registro da subjetividade dos sujeitos capacitando-os para a ação comum. A condição de abertura à alteridade implicada na experimentação política da amizade é em si mesma uma disposição a afetar e ser afetado que propicia uma relação democrática de trocas de conhecimentos de onde os sujeitos saem transformados, potencializados em seu conatus. A amizade compreendida como relação de igualdade política que não pretende anular as diferenças configura um encontro alegre implicado com o alargamento dos horizontes e aprimoramento do pensamento que aumentam a potência de agir dos sujeitos. A amizade é, portanto, um vínculo privilegiado do agir e do falarexperiências eminentemente políticas e inter-humanas, onde se dá o processo mesmo de afirmação da potência da multidão. Ou seja, a experimentação política da amizade constitui a prática da democracia como movimento de realização da liberdade, na medida em que promove os atos político do agir e falar que implicam a parceria, a companhia dos outros, a conquista da adesão dos outros mediante persuasão e não pela violência ou coerção, para que a ação desempenhe um ciclo completo de experiência inaugural, inovadora. Bove destaca a escuta da opinião do outro e o pensamento crítico - próprios da qualidade política da amizade, como modo de ser da liberdade.

Bove fala da democracia como afirmação absolutamente absoluta da potência da multidão, e que por isso mesmo ela supõe uma potência de abertura e de movimento. Ora, se abertura e movimento são condições intrínsecas à experimentação política da amizade, pode-se dizer que os laços de amizade configuram relações democráticas que favorecem a afirmação da potência da multidão a partir de um contexto dialogante aberto a trocas e práticas desencadeadoras de confrontações, deliberações e decisões.
A democracia instaura o povo como sujeito, isto é, como instância de reflexão, de confrontações de opiniões, de diálogo, e finalmente, em conhecimento de causa, de decisão. A autonomia do corpo coletivo é o acontecimento institucional e histórico da força constituinte da multidão como potência de reflexão e de decisão (Bove 3, p.258, tradução minha).

A experimentação política da amizade designa um convite a nos implicarmos com a composição de espaços democráticos de trocas de saberes e experiências onde possamos afetar e ser afetados em nossas relações cotidianas, visando a contribuir no processo coletivo de construção da cidadania. As relações de amizade podem constituir um importante exercício político de produção de espaços singulares de diálogo e ação coletiva implicados com práticas solidárias e com afetos de alegria que possam viabilizar o processo de realização de um projeto político de autonomia. De fato, a amizade como vínculo privilegiado de abertura à alteridade num contexto de igualdade política possibilita a experimentação e aprendizagem da consideração e escuta do outro, bem como do agir acompanhado e da relativização do pensamento. É na trama das relações cotidianas que a amizade pode compor vínculos de experimentação de modos outros de viver comprometidos com práticas criativas de solidariedade e resistência viabilizadoras da benevolência e da indignação que podem irromper ações políticas inovadoras. As relações de amizade como espaço "agonístico" de experimentação política, no qual os sujeitos podem questionar-se e variar pontos de vista fixos, compõem laços cuja potência subversiva aponta para a emergência de novos sujeitos sociais e novas formas de relacionamento.

A experimentação política da amizade tem como marca a imprevisibilidade e esse caráter processual da criação de modos singulares 
de relacionamentos e invenção de novas maneiras de afirmação e organização do corpo coletivo. O processo ético-político de Espinosa se inscreve nesse movimento de democracia no ato mesmo de resistência à tristeza e de produção de modos outros de estar no mundo favoráveis à afirmação da potência da multidão. É no registro da micro-política que as relações de amizade podem compor laços de confiança que mobilizam a ação comum e a produção de modos outros de estar no mundo que se dá no ato mesmo de resistência - compreendida no sentido espinosano como direito inalienável à auto-organização do corpo coletivo. Segundo Bove, a democracia encontra seu princípio ontológico na confiança, ou seja, a democracia é expressão da confiança do corpo coletivo em si mesmo, em sua própria potência. Essa confiança na potência de auto-organização da multidão é condição de possibilidade da composição de alianças singulares que garantem a existência do corpo coletivo e fortalecem sua capacidade de agir. "Se dois indivíduos se unem conjuntamente e associam suas forças, eles aumentam assim sua potência e por consequência seu direito; e quanto mais houver indivíduos que formaram alianças, mais todos juntos terão direito" (Espinosa 10, p. 126, tradução minha).

Essa ontologia da confiança como condição da democracia nos conduz à reflexão da importância da amizade como relação privilegiada de experimentação política de processos democráticos no ato mesmo de formação de alianças implicadas com afetos de alegria na criação de práticas singulares de solidariedade e de afirmação da cidadania.

\section{POLITICAL EXPERIMENTATION OF FRIENDSHIP FROM SPINOZA'S THEORY OF AFFECTS}

Abstract: Friendship is conceived in this study as having a political sense, since the consideration of the other's opinions is one of the necessary conditions of political practice. In its political sense, friendship favors the questioning of fixed points of view and the eruption of innovative actions. The political experimentation of friendship is an agonistic relationship, a relationship of opening to the other in which bodies are willing to affect and to be affected, committed to contribute to the increase of the friend's capacity for reflection and action. This paper aims to discuss the political experimentation of friendship taking as starting point Spinoza's theory of affects: the body is essentially relational and is in its relation to the others, in how it affects and is affected by them, that is given the condition of possibility of resistance to sadness and affirmation of joy - understood as increase of the power of thinking and acting.

Keywords: friendship, experimentation, politics, affects, Spinoza.

\section{REFERÊNCIAS BIBLIOGRÁFICAS}

1. ARENDT, H. A Dignidade da Política: ensaios e conferências. Tradução Helena Martins e outros. $3^{\mathrm{a}}$ ed. Rio de Janeiro: Relume Dumará, 1993.

2. ARENDT, H. A Condição Humana. Tradução de Roberto Raposo, posfácio de Celso Lafer. 10 $0^{\mathrm{a}}$ ed. Rio de Janeiro: Forense Universitária, 2001.

3. BOVE, L. La Stratégie du Conatus. Affirmation et résistance chez Spinoza. Paris. Librairie Philosophique J. VRIN, 1996.

4. BOVE, L. Introduction. Em : Spinoza. Traité Politique. Collection Classiques de la Philosophie dirigée par Jaen-François Balaudé. Traduction d'É. Saisset, revue par Laurent Bove. Introduction et notes par Laurent Bove. Libraire Générale Française, 2002.

5. CHAUI, M. de S. “Amizade, Recusa do servir”. Em: Santos, L. G. e outros. Discurso da Servidão Voluntária. Etienne de La Boétie. São Paulo: Brasiliense, 1999. p. 173- 239.

6. CHAUI, M. de S. Política em Espinosa. São Paulo: Companhia das Letras, 2003.

7. CHAUI, M. de S. Espinosa: uma filosofia da liberdade. $2^{\mathrm{a}}$ Ed. São Paulo: Moderna, 2005.

8. CHAUI, M. de S. Desejo, Paixão e Ação na Ética de Espinosa. Companhia das Letras, São Paulo, 2011.

9. DERRIDA, J. Politics of Friendship. Translated by George Collins. New York. Verso, 1997.

10. ESPINOSA, B. Spinoza. Traité Politique. Collection Classiques de la Philosophie dirigée par Jaen-François Balaudé. Traduction d'É. Saisset, revue par Laurent Bove. Introduction et notes par Laurent Bove. Libraire Générale Française, 2002.

11. ESPINOSA, B. Spinoza. Ética. $2^{\text {a }}$ edição. Tradução de Tomaz Tadeu. Belo Horizonte: Autêntica Editora, 2008

12. FOUCAULT, M. Ética, Sexualidade, Política. Organização e seleção de textos 
Manoel Barros da Motta; tradução Elisa Monteiro, Inês Autran Dourado Barbosa. Rio de Janeiro: Forense Universitária, 2004.

13. GOMES, L.G.N. \& SILVA JUNIOR, N. da. "Experimentação política da amizade: alteridade e solidariedade nas classes populares". Psicologia: Teoria e Pesquisa. v. 23 (2), p.149-158, 2007.

14. HARDT, M. Gilles Deleuze - um aprendizado em filosofia. Tradução de Sueli Cavendish. São Paulo: Ed. 34, 1996.

15. LÉVINAS, E. Humanismo do outro Homem. Tradução Pergentino S. Pivatto (Coord.) e outros. Petrópolis, RJ: Vozes, 1993.

16. LÉVINAS, E. Entre Nós. Ensaios sobre a alteridade. $2^{\text {a }}$ ed. Tradução Pergentino S. Pivatto (Coord.) e outros. Petrópolis, RJ: Vozes, 2005.

17. ORTEGA, F. Para uma política da amizade: Arendt, Derrida, Foucault. Rio de Janeiro: Relume Dumará, 2000.

\section{NOTAS}

1. De acordo com Bove (1996) o sujeito ético, projeto humano por excelência, se define pela intencionalidade amorosa que é a dinâmica da alegria ela mesma que vai se ampliando até a beatitude.

2. palavra Hilaritas de origem latina foi traduzida, na versão bilíngue latim/português por Tomaz Tadeu (2008), como contentamento. Na conversa de Bove com Paul Singer (2010) sobre o espinosismo em face da economia solidária, Bove disse que a tradução desta palavra para o francês é sempre insatisfatória e no seu livro La Stratégie du Conatus affirmation et résistence chez Spinoza, ora ele utiliza a palavra Hilaritas sem traduzi-la, ora refere-se a ela como allégresse ou gaieté.

3. "Nós nos esforçamos, tanto quanto pudermos, por livrar de sua desgraça uma coisa que nos causa comiseração". (E. III, corolário 3 da preposição 27, p.195).

4. E.I. definição 2, p.13

\section{GENEALOGIA DO PSÍQUICO. ENSAIO SOBRE A TRANSCENDÊNCIA DO EGO - ESBOÇO DE UMA DESCRIÇÃO FENOMENOLÓGICA, DE JEAN-PAUL SARTRE, PRIMEIRA PARTE}

Alexandre de Oliveira Carrasco*

Resumo: O texto em questão apresenta o primeiro esboço de uma pesquisa mais ampla acerca da "Transcendência do Ego", de J.-P. Sartre. Seu desenvolvimento, ora apresentado, pretende articular o sentido mais geral da fenomenologia de Husserl com a aclimatação, algo abruta, feita por Sartre, no referido texto, da fenomenologia husserliana. Para isso, há que se levar em conta, parece-nos, tanto os problemas propriamente sartreanos que orientam seus interesses teóricos e a dita aclimatação, quanto os limites propriamente husserlianos para tal.

Palavras-chave: Sartre, Husserl, ego, liberdade.

\section{Preâmbulo}

O texto "Transcendência do ego - esboço de uma descrição fenomenológica" pode ser considerado o marco zero da identidade filosófica de Sartre. Tal afirmação, como é de se imaginar, não se deve apenas às razões cronológicas - o primeiro texto propriamente filosófico e de larga visada escrito pelo autor. Sabe-se, ademais, que ele forma um díptico com outro ancestral texto sartreano, a "Idéia fundamental da fenomenologia de Husserl: a intencionalidade", e que ambos, muito provavelmente, foram, senão escritos, pelo menos pensados muito próximos no tempo, 